\title{
Clinical Psychophysics
}

\author{
F W FITZKE
}

London

\section{Summary}

New developments in clinical psychophysics allow a non-invasive assessment of visual function which may otherwise not be possible. Measurements of spatial and temporal contrast sensitivity functions, perimetric rod and cone sensitivity, colour vision testing, and newer tests such as hyperacuity thresholds may provide information about the mechanism of an abnormality, allow earlier detection of damage, determination of retinal function in the presence of ocular media disturbances, and allow more sensitive detection of the effects of treatment on visual function. Some methods are more effective in screening or monitoring patients over time while others can be used as research tools to investigate the underlying causes of visual dysfunction. Emerging technologies such as those based on video displays and computer generated graphics and advances in methodology provide potential for new applications. The selection of which aspect of visual function to test depends on the condition (e.g., retinal degeneration or glaucoma), the goals of the investigation, and the facilities available. These non-invasive methods can provide accurate information about retinal function and further improve our ability to quantify and document this most important aspect of the eye - its role in visual function.

Psychophysical measurements of visual function include conventional measurements such as Snellen acuity, visual fields, and colour vision. More recently newer types of testing such as spatial and temporal contrast sensitivities and hyperacuity thresholds have been introduced. These provide additional information about the function of the visual system beyond that provided by conventional tests. A great strength of these studies is that they are generally noninvasive, and they allow quantitative investigation of the abnormality of the visual system in patients which might not otherwise be attainable. A major difficulty of the subjective nature of the tests is that they require the co-operation of the patient and not all patients are able to provide accurate data. However, modern techniques can provide reliable data from most patients and the degree of reliability can be assessed to allow a measure of the validity of the results.
It is important to remember that these tests measure the function of the visual system as a whole (i.e., the optics, the retina, and the higher centres of the central nervous system) and before any conclusions can be drawn about the locus of a visual defect, the potential contribution of the other elements must be considered. As an example, if the sensitivity of the dark adapted periphery of the eye is measured to monochromatic light of different wavelengths, the normal eye would be expected to show a peak near $500 \mathrm{~nm}$ and the shape of the function should be similar to that of the rhodopsin absorption spectrum. However, we would expect a reduction of sensitivity at the shorter wavelengths due to absorption by the crystalline lens and this can be accounted for if necessary. A further reduction of sensitivity would be expected in the shorter wavelengths if the measurements are made within the macular region where macular pigment could modify the shape of the curve. 
This too can be taken into account if the measurements are made in this region. Since the task of the subject is just to report the detection of a flash of light (which would typically appear colourless), without considering any aspect of the quality of the stimulus, we would expect little effect of central nervous system factors on the overall shape of the function. Higher order effects would mainly be expected to act on the reliability of the measurement at each wavelength ("noise").

The following is intended to provide an overview of some of the newer clinical tests of visual function using psychophysical methods and will discuss some of the considerations required for interpreting the results of these tests. In particular, which types of tests may be more informative in different conditions and what kinds of questions may be answered will be discussed. Psychophysical tests, for all their difficulties, remain important and cannot be entirely replaced by more objective tests. While other investigations of the eye provide important information, some require the results of psychophysical measurements to be fully useful (i.e., reflection densitometry) and some are only indirect measures. For example, in determining whether an eye is suffering from glaucomatous damage measurement of intraocular pressure does not tell us whether there is loss of vision. Further, while a treatment may be effective in reducing intraocular pressure, its efficacy in sparing visual function may not be simply related to its pressure reducing effects. The final determining factor in deciding whether damage is occurring or hindered must be in the degree to which visual function is affected. Hence accurate methods for clinical measures of visual function remain critically important.

\section{Spatial Contrast Sensitivity}

A recent excellent series of articles has appeared on the subject of the spatial contrast sensitivity function (CSF). ${ }^{1-9}$ It has been used in ocular hypertension ${ }^{10}$ and applied to the problem of optic neuritis. ${ }^{11}$ Typically, a series of gratings of differing spatial frequencies is varied in contrast to find the threshold for visibility. The resulting curve of contrast sensitivity versus spatial frequency characteristically shows a peak in the medium spatial frequency range $(5-10 \mathrm{cpd})$ with a drop-off in sensitivity at both lower and higher values. At the high frequency limit near $30 \mathrm{cpd}$ a contrast approaching $100 \%$ is required and this corresponds to visual acuity measured by the Snellen chart. Recent work has suggested a discrete loss of sensitivity at some intermediate spatial frequencies, ${ }^{12}$ a possible relation to childhood amblyopia, ${ }^{13,14}$ and effects of cycloplegia. ${ }^{15}$ Contrast sensitivities at lower spatial frequencies provide additional information in that in some conditions, a loss of low frequency sensitivity has been reported with normal high frequency sensitivity and visual acuity. ${ }^{4}$ There is an additional importance in finding a loss of lower spatial frequency contrast sensitivity in the presence of normal higher spatial frequency contrast sensitivity in that this provides evidence for non-optical factors as the basis of the loss of sensitivity.

This introduces one of the major problems of measuring the CSF; that is, the problem of controlling the contribution of the optics. Refractive error has a substantial effect on the high frequency region of the contrast sensitivity function. ${ }^{16}$ This implies that if a retinal basis for a loss of contrast sensitivity is to be inferred, any refractive errors of the eye must be well corrected. For the case of simple refractive error the correction can be made but must be done carefully, including compensation for the viewing distance of the test. This is especially important for older presbyopic individuals. However, even if refractive error is carefully corrected, there remain potential optical errors which could affect the CSF. Pupil size could reduce high frequency contrast sensitivity due to diffraction effects if the pupil is unusually small (e.g. in the older subject with a miotic pupil or in a patient treated with pilocarpine). It could have a similar effect if the pupil is unusually large because spherical and higher order optical aberrations become more important. These optical errors can often not be fully corrected. Some techniques can, in part, bypass some of the optical errors of the eye. These include the use of laser interferometry ${ }^{17}$ and otherwise projecting grating images through the pupil. ${ }^{18}$ However, these require a clear region of the lens and are not unaffected by scattering bodies or lens alterations. It is for these reasons that great care must be taken in interpreting the results of spatial contrast sensitivity measurements in clinical applications. 


\section{Temporal Contrast Sensitivity}

Temporal contrast sensitivity provides the time varying analog of the spatial contrast sensitivity function. It is usually represented as the contrast sensitivity as a function of flicker frequency in cycles per second. Especially in photopic conditions, patients will often report that the decision of whether a stimulus is flickering is an easy one to make. It has proven to show early abnormalities in glaucoma and ocular hypertension ${ }^{19}$ and in light of our current understanding of magno- and parvo-cellular systems of the primate visual system holds considerable further potential. Rod and cone mediated flicker sensitivity in the dark adapted eye has shown early dysfunction in $\mathrm{RP}^{20}$ and has proven useful in detecting carriers of X-linked RP. ${ }^{21}$ However, in the dark adapted eye, scotopic sine wave flicker can be a difficult judgement to make, particularly at the low flicker frequencies which characterise rod mediated flicker sensitivity. An interesting rod-cone interaction has recently been found ${ }^{22,23}$ which has been shown to be abnormal in some retinal dysfunctions and is the subject of active investigation.

\section{Perimetry}

Some tests of visual function are inherently photopic while others are scotopic so that for example, measurements of colour vision using colour matching essentially involve foveal cone function while measurements of absolute threshold perimetry generally reflect rod mediated function. However, the distinction sometimes is not so clear, so that absolute threshold sensitivity to a long wavelength, small area (i.e. 20 minutes of arc) stimulus in the fovea may be cone mediated but outside the fovea may be rod mediated. The wavelength composition, temporal properties and other characteristics of the stimulus can be selected to emphasise the relative contribution of the rods and the cones and thereby provide a measure of photopic and scotopic function.

Photopic (or mesopic) perimetry has undergone a revolution and been rejuvenated with the advent of computerised perimeters. ${ }^{24,25}$ Glaucomatous visual field loss has been a major source of interest in this type of perimetry. Much activity has centered around controlling potentially confounding variables in detecting scotomas. These include the effects of defocus, ${ }^{26,27}$ comparing serial measurements, ${ }^{28}$ and the problem of variability, ${ }^{29}$ the effects of age,${ }^{30}$ the use of various stimulus sizes $^{31}$ and various stimulus spacing, ${ }^{32}$ the effects of light scatter, ${ }^{33}$ fluctuations using different perimeters, ${ }^{34}$ factors affecting LED (light emitting diode) perimetry, ${ }^{36}$ the effects of drugs which constrict the pupil, ${ }^{36}$ and peripheral field testing. ${ }^{37,38} \mathrm{~A}$ view which has emerged is the difference in character of field loss ${ }^{39,40,41}$ with diffuse and localised aspects which may be related to the similar changes seen in the nerve fibre layer.

Recent work includes early effects of glaucomatous damage, ${ }^{42}$ effects on central vision, ${ }^{43}$ the representation of data in pseudo 3 dimensional format, ${ }^{44}$ automated kinetic perimetry, ${ }^{45}$ acuity perimetry, ${ }^{46}$ scotopic perimetry in glaucoma, ${ }^{47}$ high pass resolution perimetry, ${ }^{48}$ and peripheral displacement thresholds ${ }^{49}$ which may be considered a form of hyperacuity motion perimetry. New types of testing have shown some potential for earlier detection of damage. The role of newer methods is still evolving and the effects of potentially confounding variables will have to be investigated as well as their appropriateness for general clinical use. Like more conventional field testing, the effects of optical error, pupil size, ocular media changes, age, and other factors require consideration and some newer tests may suffer from poor patient acceptance or excessive testing time. Nonetheless, there is a clear need for improvement in photopic perimetry and this promises to be an active area in the near future.

\section{Colour vision}

A recent book on defective colour vision ${ }^{50}$ and the proceedings of a meeting on colour vision deficiencies ${ }^{51}$ provide evidence of the continued activity in this area. An especially good review has just appeared ${ }^{52}$ which covers current basic research in this area which will no doubt have an important impact on clinical questions in the near future. An excellent discussion of acquired colour vision defects in glaucoma has also recently been published. ${ }^{53}$ Comparisons have been made of colour vision to retinal nerve fibre layer appearance, ${ }^{54}$ age and perimetry, ${ }^{55}$ and area of visual field. ${ }^{56}$

A different type of approach is that where the blue mechanism has been investigated in terms of sensitivity changes (i.e., in glaucoma and 
ocular hypertension ${ }^{57-59}$ ) which includes measurements made at different retinal locations in the macular region. Measurements of short wavelength cone sensitivities have been made in the ageing eye $\mathrm{e}^{60-61}$ and in macular oedema of the diabetic eye. ${ }^{62}$ In general, colour vision measurements must consider the effects of the yellowing of the crystalline lens and ageing. ${ }^{63,64}$ These reports of a particular susceptibility of the blue mechanism promise considerable potential.

\section{Retina}

Clinical investigations of the function and malfunction of the retinal degenerations have benefitted substantially from the use of non-invasive techniques such as psychophysics and fundus reflectometry. Much can be learned about the underlying causes of the loss of vision from these new methods. It is vital to co-ordinate these different types of studies to answer questions about the underlying causes of the dysfunctions. For example, if we wish to know whether the loss of night vision in a retinal degeneration is entirely due to loss of rhodopsin in the photoreceptors or whether the defect involves a more proximal mechanism such as the neural elements of the retina, we must correlate the threshold elevation with the measured rhodopsin.

Patients with retinitis pigmentosa (RP) have been extensively studied in terms of genetic type, clinical findings, retinal function measured electrophysiologically and physchophysically, and by fundus reflectometry. Several important findings have emerged ${ }^{65,66}$ and a number of instruments have been developed for making perimetric measurements in scotopic conditions. ${ }^{67-69}$ It is clear that within genetic types there are fundamentally different forms of disease which are consistent among family members. One form shows diffuse loss of rod function ("D" type) throughout the retina while cone function may be nearly normal until later in the disease. In the other form there is concomitant loss of rod and cone function in retinal regions (" $R$ " type) with areas where rod and cone function can be nearly normal early in the disease coexisting with regions of severely abnormal rod and cone function. ${ }^{70-71}$ Further there are fundamental differences in the relation between rhodopsin and sensitivity. ${ }^{72-74}$ In the "D" type relatively substantial amounts of rhodopsin can be measured even where retinal sensitivity is severely reduced while the " $R$ " type the loss of rhodopsin can account entirely for the sensitivity loss. These findings suggest fundamentally different processes and the classification of RP families into pure RP type is important for understanding disease mechanisms and for interpreting the results of other studies. The relation between rhodopsin levels and scotopic sensitivity has also been investigated in humans with sector $\mathrm{RP},{ }^{75}$ choroideremia ${ }^{76}$ and vitamin A deficiency. ${ }^{77}$

Variations in delayed rates of dark adaptation have been found in some regions of the retina of Sorsby's fundus dystrophy. ${ }^{78}$ This was attributable to the corresponding rhodopsin regeneration rate which was also found to be delayed. Severely delayed dark adaptation has been found in some patients with $\mathrm{RP}^{79,80}$ with a time course of hours or even days. This similarity in time course to that of the outer segment renewal mechanism could reflect the effects of an underlying abnormality of shortened outer segments. It has been suggested that an abnormality in the balance between outer segment renewal and phagocytosis may be involved in $\mathrm{RP}^{81}$ and these non-invasive techniques may provide a means of indirectly measuring these processes in patients. Abnormal diurnal variation in visual sensitivity in patients with retinal oedema has been measured $^{82}$ and reports of abnormalities in sensitivity with a daily variation ${ }^{83}$ suggest that we may be able to relate abnormalities in RP patients to animal findings of diurnal rhythms of outer segment renewal mechanisms which could be tested by manipulating the light-dark cycle in patients. Absolute threshold measurements have shown interesting abnormalities in age related macular degeneration ${ }^{84,85}$ and techniques of measuring scotopic function ${ }^{86}$ hold much promise for the near future.

\section{Video display devices}

A strong new area of technology involves the use of video display units (VDUs) for testing. These have long been used as psychophysical stimulus generators. ${ }^{87-94}$ Although a variety of psychophysical measurements ${ }^{95-97}$ have been made, perimetric threshold determinations have only recently been attempted ${ }^{98-103}$ and it is necessary further to develop and test the technology. ${ }^{104-111}$

Computer generated graphics and video 
display units have an important appeal in that they allow the use of a great variety of stimuli of different form, spatial configuration, spectral composition, location and other factors determined simply by a mathematical expression describing their characteristics. This removes the limitations to a large extent of the hardware changes which would otherwise be needed to alter these parameters. Of course, there are some kinds of stimuli which are better formed using other techniques (e.g., narrow wavelength band stimuli). However, some measurements which would otherwise be prohibitively tedious or have been impossible to perform in the past are now possible using computer generated graphics. These include such potential tests as movement sensitivity, iso-luminant colour stimuli, flashes of "darkness", and others. These new types of tests may allow more selective and sensitive measures of the function of the visual system while the technology makes it easy to implement the new tests.

Retinal abnormalities have been further investigated on a microscopic scale using the newly developed technique of fine matrix perimetry to further characterise retinal function with higher spatial resolution. ${ }^{12,113,78}$ These measurements are made using video displays and computer generated graphics with methods to control the optics of retinal image formation ${ }^{114-117}$ and eye movements and using computer image analysis and processing of the data. These measurements are correlated with rhodopsin density measurements to allow further characterisation of the retinal abnormalities on a microscopic scale in particular at the edge of the advancing front of the degeneration and on the borders between nearly normal and severely affected retina. ${ }^{118}$

\section{Statistics and screening}

For all of these tests an important component which must not be overlooked is the design and interpretation using statistical methods. ${ }^{119-123}$ It is also useful to consider the implications of screening tests ${ }^{124,125}$ for such common diseases as glaucoma.

\section{Newer tests}

Emergent techniques for the assessment of visual performance have recently been reviewed ${ }^{126}$ and there has been considerable activity in the development of newer types of testing which would be expected to have a greater impact in the near future. One test incorporates the stimulus into a fundus camera, ${ }^{127}$ another uses colour matching to estimate foveal cone pigment optical density, ${ }^{128}$ the flash-on-flash paradigm suggested that loss of foveal sensitivity in some patients with RP could not be attributed to decreased quantum catch, ${ }^{129}$ static and kinetic perimetry have been combined into one test, ${ }^{130}$ and hyperacuity testing ${ }^{131-134,49}$ has shown a new approach of measuring spatial vision with little artefactual susceptibility to optical errors. Recent advances in our understanding about the pathological changes of some abnormalities ${ }^{135}$ combined with knowledge of the visual system $^{136}$ suggest new approaches to detect damage at an earlier stage, provide information about the mechanism of an abnormality, the determination of retinal function in the presence of ocular media disturbances, and the effects of treatment on visual function. Emerging technologies such as those based on video displays and computer generated graphics and advances in methodology provide potential for new applications. These non-invasive methods can provide accurate information about retinal function and further improve our ability to quantify and document this most important aspect of the eye - its role in visual function.

\section{References}

' Kersten D, Hess RF, Plant GT. Assessing contrast sensitivity behind cloudy media. Clin Vision Sci 1988; 2: 143-58.

${ }^{2}$ Abrahamsson $\mathbf{M}$, Frisen $\mathbf{M}$, Sjöstrand J. Statistical evaluation of contrast sensitivity function (CSF) in visual disorders - can diagnostic indices of CSF and acuity data be clinically useful? Clin Vision Sci 1988; 2: 159-67.

${ }^{3}$ Rubin GS. Reliability and sensitivity of clinical contrast sensitivity tests. Clin Vision Sci 1988; 2: 169-77.

${ }^{4}$ Tytla ME, and Buncic JR. Optic nerve compression impairs low spatial frequency vision in man. Clin Vision Sci 1988; 2: 179-86.

${ }^{5}$ Pelli DG, Robson JG, Wilkins AJ. The design of a new letter chart for measuring contrast sensitivity. Clin Vision Sci 1988; 2: 187-99.

${ }^{6}$ Wilkins AJ, Della Sala S, Somazzi L, NimmoSmith I. Age-related norms for the Cambridge Low Contrast Gratings, including details concerning their design and use. Clin Vision Sci 1988; 2: 201-12. 
${ }^{7}$ Arden GB. Testing contrast sensitivity in clinical practice. Clin Vision Sci 1988; 2: 213-34.

${ }^{8}$ Barbur JL. Spatial frequency specific measurements and their use in clinical psychophysics. Clin Vision Sci 1988; 2: 225-33.

${ }^{9}$ Regan D. Low-contrast charts and sinewave grating tests in ophthalmological and neurological disorders. Clin Vision Sci 1988; 2: 235-50.

${ }^{10}$ Ross JE, Bron AJ, Reeves BC, Emmerson PG. Detection of optic nerve damage in ocular hypertension. Br J Ophthalmol 1985; 69: 897-903.

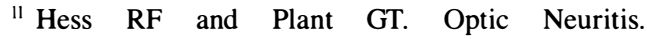
Cambridge. Cambridge University Press, 1986.

${ }^{12}$ Apkarian P, Tjissen R, Spekreijse H, Regan D. Origin of notches in CSF: optical or neural? Inv Ophthalmol Vis Sci 1987; 28: 607-12.

${ }^{13}$ Kowal L. The contrast sensitivity function and childhood amblyopia. Am J Ophthalmol 1987; 104: 671-2.

${ }^{14}$ Rogers GL, Bremer DL, Leguire LE. Reply to the contrast sensitivity function and childhood amblyopia. Am J Ophthalmol 1987; 104: 672-3.

${ }^{15}$ Bachman WG, and Behar I. The effect of cycloplegia on the visual contrast sensitivity function. Aviat Space Environ Med 1987; 58: $339-42$.

${ }^{16}$ Campbell FW and Green DG. Optical and retinal factors affecting visual resolution. $J$ Physiol Lond 1965; 181: 576-93.

${ }^{17}$ Green DG. Testing the vision of cataract patients by means of laser-generated intereference fringes. Science 1970; 168: 1240-2.

${ }^{18}$ Cavonius CR, and Hilz R. A technique for testing visual function in the presence of opacities. Invest Ophthalmol Vis Sci 1973; 12: 933-6.

${ }^{19}$ Tylder CW. Specific deficits of flicker sensitivity in glaucoma and ocular hypertension. Invest Ophthalmol Vis Sci 1981; 20: 204-12.

${ }^{20}$ Tyler CW, Ernst W, Lyness AL. Photopic flicker sensitivity losses in simplex and multiplex retinitis pigmentosa. Invest Ophthalmol Vis Sci 1984; 25: 1035-42.

${ }^{21}$ Ernst W, Clover G, Faulkner DG. X-linked retinitis pigmentosa: reduced rod sensitivity to flicker in heterozygous females. Invest Ophthalmol Vis Sci 1982; 20: 812-6.

${ }^{22}$ Alexander KR and Fishman GA. Rod-cone interaction in flicker perimetry. $\mathrm{Br} J$ Ophthalmol 1984; 68: 303-9.

${ }^{23}$ Arden GB and Hogg CR. Rod-cone interaction and analysis of retinal disease. Br J Ophthalmol 1985; 69: 404-15.

${ }^{24}$ Greve EL and Heijl A. Seventh International Visual Field Symposium. Dordrecht, Martinus Nijhoff/Dr W Junk, 1987: 675.
${ }^{25}$ Silverstone DE and Hirsch J. Automated visual field testing. Norwalk, Conn. Appleton-CenturyCrofts, 1986: 308.

${ }^{26}$ Atchison DA. Effect of defocus on visual field measurement. Ophthal Physiol Opt 1987; 7: 259-65.

${ }^{27}$ Weinreb RN, and Perlman JP. The effect of refractive correction on perimetric thresholds. Am J Ophthalmol 1986; 101: 706-9.

${ }^{28}$ Wood JM, Wild JM, Hussey MK, Crews SJ. Serial examination of the normal visual field using Octopus automated projection perimetry: Evidence for a learning effect. Acta Ophthalmol 1987; 65: 326-33.

${ }^{29}$ Lewis RA, Johnson CA, Keltner JL, Labermeier PK. Variability of quantitative automated perimetry in normal observers. Ophthalmology 1986; 93: 878-81.

${ }^{30}$ Jaffe GJ, Alvarado JA, Juster RP. Age-related changes of the normal visual field. Arch Ophthalmol 1986; 104: 1021-5.

${ }^{31}$ Wilensky JT, Mermelstein JR, Siegel HG. The use of different-sized stimuli in automated perimetry. Am J Ophthalmol 1986; 101: 710-13.

${ }^{32}$ Sturmer J. What do glaucomatous visual fields really look like in fine-grid computerized profile perimetry. Dev Ophthalmol 1985; 12: 1-47.

${ }^{33}$ Wood JM, Wild JM, Crews SJ. Induced intraocular light scatter and the sensitivity gradient of the normal visual field. Graefe's Arch Clin Exp Ophthalmol 1987; 225: 369-73.

${ }^{34}$ Brenton RS and Argus WA. Fluctuations on the Humphrey and Octopus perimeters. Invest Ophthalmol Vis Sci 1987; 28: 767-71.

${ }^{35}$ Wood JM, Wild JM, Bullimore MA, Gilmartin B. Factors affecting the normal perimetric profile derived by automated static threshold LED perimetry. I. Pupil size. Ophthal Physiol Opt 1988; 8: 26-31.

${ }^{36}$ McCluskey DJ, Douglas JP, O'Connor PS, Story K, Ivy LM, Harvey JS. The effect of pilocarpine on the visual field in normals. Ophthalmology 1986; 93: 843-6.

${ }^{37}$ Stewart WC, Shields MB, Ollie AR. Peripheral visual field testing by automated kinetic perimetry in glaucoma. Arch Ophthalmol 1988; 106: 202-6.

${ }^{38}$ Wirtschafter JD. Examination of the peripheral visual field. Arch Ophthalmol 1987; 105: 761-2.

${ }^{39}$ Capriolo J, Sears M, Miller JM. Patterns of early visual field loss in open-angle glaucoma. $A m \mathrm{~J}$ Ophthalmol 1987; 103: 512-7.

${ }^{40}$ Katz J and Sommer A. Similarities between the visual fields of ocular hypertensive and normal eyes. Arch Ophthalmol 1986; 104: 1648-51.

${ }^{41}$ Drance SM, Douglas GR, Airaksinen PJ, Schulzer M, Hitchings RA. Diffuse visual field loss in 
chronic open-angle and low tension glaucoma. Am J Ophthalmol 1987; 104: 577-80.

${ }^{42}$ Lewis RA and Johnson CA. Early detection of glaucomatous damage. I. Psychophysical disturbances. Surv Ophthalmol 1985; 30: 111-7.

${ }^{43}$ Stampfer RL. The effect of glaucoma on central visual function. Trans Am Ophthalmol Soc 1984; 82: $792-826$.

44 Wild JM, Wood JM, Worthington FM, Crews SJ. Some concepts on the use of three-dimensional plots for the representation of differential sensitivity. Doc Ophthalmol 1987; 65: 423-32.

45 Johnson CA, Keltner JL, Lewis RA. Automated kinetic perimetry: and efficient method of evaluating peripheral visual field loss. Appl Optics 1987; 26: 1409-14.

${ }^{46}$ Phelps CD. Acuity perimetry and glaucoma. Trans Am Ophthalmol Soc 1984; 82: 753-91.

${ }^{47}$ Drum B, Armaly MF, Huppert W. Scotopic sensitivity loss in glaucoma. Arch Ophthalmol 1986; 104: 712-17.

${ }^{48}$ Frisen L. a computer-graphics visual field screener using high-pass, spatial frequency resolution targets and multiple feedback devices. In Greve EL and Heyl A, eds. Seventh International Visual Field Symposium 1986; 441-446.

${ }^{49}$ Fitzke FW, Poinoosawmy D, Ernst W, Hitchings RA. Peripheral Displacement Thresholds in Normals Ocular Hypertensives, and Glaucoma. In Greve EL and Heyl A, eds. Seventh Int. Visual Field Symposium 1986; 447-452.

${ }^{50}$ Fletcher R and Voke J. Defective colour vision. Bristol and Boston, Adam Hilger Ltd, 1985: 608.

${ }^{51}$ Verriest G, ed. Colour Vision Deficiencies VIII. Martinus Nijhoff/Dr W Junk, 1987: 524.

52 Boynton RM. Colour vision. Ann Rev Psychol 1988; 39: 69-100.

53 Sample PA, Weinreb RN, Boynton RM. Acquired dyschromatopsia in glaucoma. Surv Ophthalmol 1986; 31: 54-64.

${ }^{54}$ Airaksinen PJ, Lakowski R, Drance SM, Price M. Color vision and retinal nerve fibre layer in early glaucoma. Am J Ophthalmol 1986; 101: 208-13.

55 Breton ME and Krupin T. Age covariance between 100-hue colour scores and quantitative perimetry in primary open angle glaucoma. Arch Ophthalmol 1987; 105: 642-5.

${ }^{56}$ Chisholm IA. Area of visual field and colour discrimination combined as a predictor of chronic open-angle glaucoma. Can J Ophthalmol 1988; 23: 8-10.

${ }^{57}$ Heron G, Adams AJ, Husted R. Foveal and nonfoveal measures of short wavelength sensitive pathways in glaucoma and ocular hypertension. Ophthal Physiol Opt 1987; 7: 403-4.
58 Adams AJ, Heron G, Husted R. Clinical measures of central vision function in glaucoma and ocular hypertension. Arch Ophthalmol 1987; 105: 782-7.

${ }^{59}$ Heron G, Adams AJ, Husted R. Central visual fields for short wavelength sensitive pathways in glaucoma and ocular hypertension. Inv Ophthalmol Vis Sci 1988; 29: 64-72.

${ }^{60}$ Eisner A, Fleming SA, Klein ML, Mauldin WM. Sensitivities in older eyes with good acuity: cross sectional norms. Inv Ophthalmol Vis Sci 1987; 28: 1824-31.

${ }^{6 l}$ Applegate RA, Adams AJ, Cavender JC, Zisman F. Early colour vision changes in age-related maculopathy. Appl Optics 1987; 26: 1458-62.

62 Adams AJ, Zisman F, Ai E, Bresnick G. Macular edema reduces $\mathrm{B}$ cone sensitivity in diabetics. Appl Optics 1987; 26: 1455-7.

${ }^{63}$ Pokorny J, Smith VC, Lutze M. Ageing of the human lens. Appl Optics 1987; 26: 1437-40.

${ }^{64}$ Knoblauch K, Saunders F, Kusuda M, Hynes R, Podgor M, Higgins KE, de Monasterio FM. Age and illuminance effects in the FarnsworthMunsell 100-hue test. Appl Optics 1987; 26: 1441-8.

${ }^{65}$ Massof RW and Finkelstein D. Rod sensitivity relative to cone sensitivity in in retinitis pigmentosa. Invest Ophthalmol Vis Sci 1979; 18: 263-72.

${ }^{66}$ Lyness AL, Ernst W, Quinlan MP, Clover GM, Arden GB, Carter RM, Bird AC, Parker JA. A clinical, psychophysical, and electroretinographic survey of patients with autosomal dominant retinitis pigmentosa. Br J Ophthalmol 1985; 69: 326-39.

${ }^{67}$ Ernst W, Faulkner DJ, Hogg CR, Powell DJ, Arden GB, Vaegan. An automated static perimeter/adaptometer using light emitting diodes. Br J Ophthalmol 1983; 67: 431-42.

${ }^{68}$ Apathy PP, Jacobson SG, Nghiem-phu L, Knighton RW, Parel J-M. Computer-aided analysis in automated dark-adapted static perimetry. In Greve EL and Heyl A, eds. Seventh Int Visual Field Symposium 1986; 277-284.

${ }^{69}$ Mayer DL, Fulton AB, Cummings MF. Visual fields of infants assessed with a new perimetric technique. Invest Ophthalmol and Vis Sci 1988; 29: 452-9.

${ }^{70}$ Ernst W, Kemp CM, Arden GB, Moore AT, Bryan S. Functional Heterogeneity in Retinitis Pigmentosa, in Retinal Signal Systems, Degenerations and Transplants, eds. E Agardh and B Ehinger, The Netherlands, Elsevier, 1986.

${ }^{71}$ Bird AC. Clinical investigation of retinitis pigmentosa, In: Degenerative Retinal Disorders: Clinical and Laboratory Investigations Ed. JG Hollyfield, RE Anderson, and MM LaVail. Alan R Liss, New York, 1987 pp. 3-20. 
${ }^{72}$ Kemp CM. Fundus reflectometric investigation of retinitis pigmentosa. Adv Biosciences 1987; 62: 169-76.

${ }^{73}$ Kemp CM, Jacobson SG, Faulkner DJ, Walt WW. Visual function and rhodopsin levels in humans with vitamin A deficiency. Exp Eye Res 1988; 46: 185-97.

${ }^{74}$ Kemp CM, Jacobson SG, Faulkner DJ. Two types of visual dysfunction in autosomal dominant retinitis pigmentosa. Invest Ophthalmol Vis Sci 1988; 29 (in press).

${ }^{75}$ Fulton $\mathrm{AB}$ and Hansen RM. The relation of rhodopsin and scotopic retinal sensitivity in sector retinitis pigmentosa. Am J Ophthalmol 1988; 105: $132-40$.

${ }^{76}$ Fulton $\mathrm{AB}$ and Hansen RM. The relation of rhodopsin and scotopic retinal sensitivity in choroideremia. Am J Ophthalmol 1987; 105: 524-31.

77 Kemp CM, Jacobson SG, Faulkner DJ, Walt RW. Visual function and rhodopsin levels in humans with vitamin A deficiency. Exp Eye Res 1988; 46: 185-97.

${ }^{78}$ Capon MRC, Polkinghorne PJ, Fitzke FW, Bird AC. Sorsby's Pseudoinflammatory Macula Dystrophy - Sorsby's Fundus Dystrophies. Eye 1988; 2: 114-22.

79 Alexander KR and Fishman GA. Prolonged Rod Dark Adaptation in Retinitis Pigmentosa. $\mathrm{Br} J$ Ophthalmol 1984; 68: 561-9.

${ }^{80}$ Ernst W and Moore AR Heterogeneity, anomalous adaptation and incomplete penetrance in autosomal dominant retinitis pigmentosa. $A d v$ Biosciences 1987; 62: 115-28.

${ }^{81}$ Highman VN and Weale RA. Rhodopsin density and visual threshold in retinitis pigmentosa. $\mathrm{Am}$ J Ophthalmol 1973; 75: 822-32.

${ }^{82}$ Sternberg P, Fitzke FW, Finkelstein D. Cyclic Macular Edema. Am J Ophthalmol 1982; 94: 664-9.

${ }^{83}$ Sandberg MA, Baruzzi CM, Hanson AH, Berson EL. Rod ERG diurnal rhythm in some patients with dominant retinitis pigmentosa. Inv Ophthalmol and Vis Sci 1988; 29: 494-8.

${ }^{84}$ Eisner A, Fleming SA, Klein ML, Mauldin WM. Sensitivities in older eyes with good acuity: eyes whose fellow eye has exudative AMD. Inv Ophthalmol and Vis Sci 1987; 28: 1832-7.

85 Sunness JS, Massof RW, Johnson MA, Finkelstein $\mathrm{D}$, Fine S. Peripheral retinal function in agerelated macular degeneration. Arch Ophthalmol 1985; 103: 811-6.

${ }^{86}$ Working Group on Night Vision. Night Vision. Washington DC, National Academy Press 1987; 335.

${ }^{87}$ Mayzner MS. The research potential of a computer-based cathode-ray tube display system. Behav Res Meth Instru 1968; 1: 41-3.
${ }^{88}$ Sekuler $\mathrm{R}$ and Armstrong R. Luminance control of a small computer CRT display: A very cheap technique. Behav Res Meth Instru 1971; 3: 48-9.

${ }^{89}$ Dyer FN and Schelderup JR. Adding the dimension of colour to computer-generated displays. Behav Res Meth Instru 1973; 5: 487-9.

${ }^{90}$ Polit AC. Computer generation of textures. Beh Res Meth Instru 1976; 8:367-8.

${ }^{91}$ Shapley R and Rossetto M. An electronic visual stimulator. Beh Res Meth Instru 1976; 8: 15-20.

92 Milkman N, Shapley R, Schick G. A microcomputer-based visual stimulator. Beh Res Meth Instru 1978; 10: 539-45.

${ }^{93}$ Reed AV. Microcomputer display timing: Problems and solutions . Beh Res Meth Instru 1979; 11: 572-6.

94 Cavanagh P and Anstis SM. Visual psychophysics on the APPLE II: Getting started. Behav Res Meth Instru 1980; 12: 614-26.

95 Kelly DH. Retinal inhomogeneity. I. Spatiotemporal contrast sensitivity. J Opt Soc Am 1984a; A 1: 107-113.

${ }^{96}$ Kelly DH. Retinal inhomogeneity. II. Spatial summation. J Opt Soc Am 1984b; A 1: 114-119.

${ }^{97}$ King-Smith PE, Chioran GM, Sellers KL, Alvarez SL. Normal and deficient colour discrimination analysed by colour television. In Colour Vision: Physiology and Psychophysics, ed. Mollon JD \& Sharpe LT, London, Academic Press, 1983; 167-172.

${ }^{98}$ Hamazaki S, Yokota T, Mieno H, Koike H, Koike S, Taga M, Hamazaki J, Kikuchi G, and Matsuo H. Semi-automatic campimeter with graphic display. Docum Ophthalmol Proc Ser 1978; 19: 311-17.

${ }^{99}$ Fitzke FW. Visual Psychophysics with a Video Display Controlled by a Microcomputer. $J$ Physiol 1984; 351: 6P.

${ }^{100}$ Ernst W, and Fitzke FW. Mapping Fine Retinal Detail by Measuring Visual Thresholds, ARVO Suppl. Inv Ophthalmol and Vis Sci 1984; 25 : 144.

${ }^{101}$ Accornero N, Berardelli A, Cruccu G, Manfredi M. Computerized video screen perimetry. Arch Ophthalmol 1984; 102: 40-1.

102 Hart WM and Gordon MO. Colour perimetry of glaucomatous visual field defects. Ophthalmology 1984; 91: 338-46.

${ }^{103}$ Hart WM and Burde RM. Colour contrast perimetry: The spatial distribution of colour defects in optic nerve and retinal diseases. Ophthalmology 1985; 92: 768-76.

104 Sperling G. The description and luminous calibration of cathode ray oscilloscope visual displays. Behav Res Meth Instru 1971; 3: 148-53.

${ }^{105}$ Uttal WR. Variable manufacturing characteristics of the P-15 phosphor: A warning. Behav Res Meth Instru 1973; 5: 60. 
106 Virsu V and Lehtio PK. A microphotometer for measuring luminance distributions on a CRT. Beh Res Meth Instru 1975; 7: 29-33.

${ }^{107}$ Di Lollo V. Luminous calibration of oscilloscopic displays. Behav Res Meth Instru 1979; 11: 419-21.

${ }^{108}$ Cowan WB. Discreteness artifacts in raster display systems. In Colour Vision: Physiology and Psychophysics, ed. Mollon, JD \& Sharpe LT, London, Academic Press, 1983; 145-153.

${ }^{109}$ Rodieck RW. Raster-based colour stimulators. In Colour Vision: Physiology and Psychophysics, ed. Mollon JD \& Sharpe LT, London, Academic Press, 1983; 131-144.

${ }^{110}$ Arden GB, Gunduz K, Perry S. Colour vision testing with a computer graphics system. Clin Vision Sci 1988; 4: 303-20.

${ }^{111}$ Fitzke FW PhD Thesis, University of London Spatial Properties of Scotopic Sensitivity 1986.

${ }^{112}$ Fitzke FW, Chuang EL, Holden AL, Kemp CM, Ernst W, Moore AT, Sharp DM, Bird AC. Fine Matrix Perimetry. (ARVO Suppl). Invest Ophthalmol Vis Sci 1987; 28: 113.

${ }^{113}$ Chuang EL, Sharp DM, Fitzke FW, Kemp CM, Holden AL, Bird AC. Retinal Dysfunction in Central Serous Retinopathy. Eye 1987; 1: 120-5.

${ }^{114}$ Fitzke FW, Holden AL, Sheen FH. A Maxwellianview Optometer Suitable for Electrophysiological and Psychophysical Research. Vis Res 1985; 25 : 871-4.

${ }^{115}$ Fitzke FW. A Representational Schematic Eye in, "Modelling the Eye with Gradient Index Optics", ed. A Hughes, Cambridge University Press, (in press).

${ }^{116}$ Holden AL, Hayes BP, Fitzke FW. Retinal Magnification Factor at the Ora Terminalis: a Structural Study of Human and Animal Eyes. Vision Res 1987; 27: 1229-35.

${ }^{117}$ Holden AL, and Fitzke FW. Image Size in the Fundus: Structural Evidence for Wide-field Retinal Magnification Factor. $\mathrm{Br} J$ Ophthalmol 1988; 72: 228-30.

118 Turner GS, Kemp CM, Fitzke FW, Bird AC. Rhodopsin and scotopic sensitivity in choroideremia (ARVO Suppl). Invest Ophthalmol Vis Sci 1988; 29: 314.

${ }^{119}$ Bourne WM. 'No statistically significant difference': So what? Arch Ophthalmol 1987; 105: 40-1.

${ }^{120}$ Seigel D. Regression. Arch Ophthalmol 1987; 105: $185-6$.
${ }^{121}$ Gardner MJ and Altman DS. Confidence intervals rather than $P$ values: estimation rather than hypothesis testing. $B r$ Med $J$ 1986; 292: 746-50.

122 Wild JM and Hussey MK. Statistical concepts in the analysis of vision and visual acuity. Ophthal Physiol Opt 1986; 6: 349-51.

${ }^{123}$ Ray WA and O'Day DM. Statistical analysis of multi-eye data in ophthalmic research. Invest Ophthalmol Vis Sci 1985; 26: 1186-8.

${ }^{124}$ Hitchings RA. Screening for glaucoma. $\mathrm{Br} \mathrm{Med} \mathrm{J}$ 1986; 292: 505-6.

${ }^{125}$ Olander KW, Higuchi B, Zimmerman TJ. Update on screening for glaucoma. Ann Ophthalmol 1987; 19: 366-7.

${ }^{126}$ Committee on Vision. Emergent techniques for assessment of visual performance. Washington DC, National Academy Press, 1985: 66.

${ }^{127}$ Sunness JS, Johnson MA, Massof RW, Kays DL. Wilmer fundus camera stimulator. Appl Optics 1987; 26: 1487-91.

${ }^{128}$ Elsner AE, Burns SA, Lobes LA. Foveal cone optical density in retinitis pigmentosa. Appl Optics 1987; 26: 1378-84.

${ }^{129}$ Greenstein V, Hood DC, Carr RE. Foveal sensitivity changes in retinitis pigmentosa. Appl Optics 1987; 26: 1385-9.

${ }^{130}$ Drum B. Hybrid perimetry: a blend of static and kinetic techniques. Appl Optics 1987; 26: 1415-20.

${ }^{131}$ Enoch JM, Williams RA, Essock EA, Barricks M. Hyperacuity perimetry: Assessment of macular function through ocular opacities. Arch Ophthalmol 1984; 102: 1164-8.

132 Williams RA, Enoch JM, Essock EA. The resistance of selected hyperacuity configurations to retinal image degradation. Invest Ophthalmol Vis Sci 1984; 25: 389-99.

${ }^{133}$ Enoch JM and Williams RA. Development of clinical tests of vision: Initial data on two hyperacuity paradigms. Perception and Psychophysics 1983; 33: 314-22.

${ }^{134}$ Whitaker D and Buckingham T. Theory and evidence for a clinical hyperacuity test. Ophthal Physiol Opt 1987; 7: 431-5.

${ }^{135}$ Quigley HA, Dunkelberger GR, Green WR. Chronic human glaucoma causing selectively greater loss of large optic nerve fibres. Ophthalmology 1988; 95: 357-63.

${ }^{136}$ Livingstone $M$ and Hubel D. Segregation of form, movement, and depth: anatomy, physiology, and perception. Science 1988; 240: 740-9. 